\title{
Mean-Variance Analysis of Supply Chain Contracts
}

\author{
Tsan-Ming Choi \\ The Hong Kong Polytechnic University \\ Hong Kong
}

\section{Introduction}

According to the Council of Supply Chain Management Professionals (September 2007), we have the following description for supply chain management:

"supply chain management encompasses the planning and management of all activities involved in sourcing and procurement, conversion, and all logistics management activities. Importantly, it also includes coordination and collaboration with channel partners, which can be suppliers, intermediaries, third-party service providers, and customers. In essence, supply chain management integrates supply and demand management within and across companies." From this description, it is obviously true that a supply chain in general has multiple channel members (usually called stages) and the coordination and collaboration among these members is a crucial task in supply chain management.

In the literature, various policies for supply chain optimization and channel coordination have been proposed. Among them, setting a supply chain contract between individual parties has received much attention in recent years (Tsay et al. 1999, Cachon 2003). Contracts such as buy-back contract, revenue sharing contract, quantity flexibility contract and rebates contract are all known forms of contract which can help to achieve channel coordination in a supply chain. However, in the majority of the literature works, the channels' and supply chain's objectives are either maximizing the expected profit or minimizing the expected cost. There is no discussion on the level of risk associated with these contracts. As a result, the contract parameters under which coordination is achieved may be viewed as unrealistic by decision makers. In light of this, we conduct in this paper a mean-variance analysis on some popular forms of supply chain contracts such as buy-back contract. By including a constraint $\Phi$ on profit uncertainty, we illustrate how decision makers can make a scientifically sound and tailored decision with respect to their degrees of risk aversion. Managerial implications are discussed.

The organization of the rest of this chapter is as follows: We briefly review some related of literature in Section 2, the discussion of the supply chain's structure is presented in Section 3. The mean-variance analyses on the buy-back contract and wholesale pricing profit sharing contract are conducted in Sections 4 and 5, respectively. We conclude with some discussions on managerial implications in Section 6.

For a notational purpose, we use the following notation in many places throughout this chapter: $P=$ profit, $E P=$ expected profit, $S P=$ standard deviation of profit, $M V=$ mean- 
variance. The subscripts " $M, R, S C^{\prime}$ " represent "Manufacturer, Retailer, Supply Chain", respectively.

\section{Literature review}

Pioneered by Nobel laureate Harry Markowitz in the 1950s, the mean-variance formulation has become a fundamental theory for risk management in finance (Markowitz 1959). In decision sciences, the mean-variance approach and the von Neumann-Morgenstern utility approach (called utility function approach in short) are two well established methodologies for studying decision making problems with risk concerns. The utility function approach is more precise but its application is limited owing to the difficulty in getting a closed form expression of the utility function for every individual decision maker in practice. The meanvariance approach, as what Van Mieghem (2003) mentioned, aims at providing an implementable, useful but approximate solution. It is true that a utility function in general cannot be expressed fully in terms of mean and variance only. However, it is shown in Van Mieghem (2003) that maximizing a utility function with a constant coefficient of risk aversion is equivalent to maximizing a mean-variance performance measure (also see Luenberger 1998, Choi et al. 2008 for some supplementary discussions). There are also evidences in the literature which demonstrate that the mean-variance approach yields a solution which is close to the optimal solution under the utility function approach (see Levy \& Markowitz 1979, Kroll et al. 1984, and Van Mieghem 2003). Moreover, some meaningful and applicable objectives, such as the safety first objective (Roy 1952), can be formulated under the mean-variance framework. Despite all kinds of arguments on the mean-variance approach, it is adopted as the performance measure in this chapter because it's "applicable, intuitive and implementable". In addition, more analytical results can be generated under this approach. On the other hand, even though the mean-variance and utility function approaches are well-established in finance, their applications in supply chain management are not yet fully revealed. In fact, most research works on this important topic appear only in recent years. We review some of them as follows.

First, in Lau (1980), instead of maximizing the expected profit, the author derives an optimal order quantity which maximizes an objective function of the expected profit and standard deviation of profit for the classic newsvendor problem. Next, Eechhoudt et al. (1995) study the classic newsvendor problem with risk averse newsvendor via a utility function approach and obtain some interesting findings on the optimal stocking quantity. Later on, Lau and Lau (1999) directly extend the work of Pasternack (1985) and study a single-manufacturer single-retailer supply chain model under which both the retailer and manufacturer seek to maximize a linear objective function of the expected profit and variance of profit. Choi et al. (2008) analyze via a mean-variance approach the supply chains under returns policy in both decentralized and centralized settings. Implications for setting returns contracts for achieving channel coordination with risk considerations are discussed. Some other recent research works which analyse the risk issues in supply chain management include a qualitative discussion on proactive supply management and its close relationship with risk management (Smeltzer \& Siferd 1998), a quantitative analysis of the role of intermediaries in supply chains to reduce financial risk (Agrawal \& Seshadri 2000), a mean-variance analysis of single echelon inventory problems (Chen \& Federgruen 2000), a study of the risk-free perishable item returns policy with a risk neutral retailer in a two-echelon supply chain (Webster \& Weng 2000), an investigation of the use of capacity options in managing risk 
from demand uncertainty (Tan 2002), an analysis of the use of commitment-option for supply chain contract setting with forecast updates (Buzacott et al. 2003), a study on contracting scheme with risk preferences considerations (Bassok \& Nagarajan 2004), a meanvariance analysis for the newsvendor problem with and without the opportunity cost of stock out (Choi et al. 2007a), and a study on channel coordination in supply chains under mean-variance objectives (Choi et al. 2007b)

\section{Supply chain model}

Consider a two-echelon supply chain with one manufacturer and one retailer. The retailer sells a fashionable product and faces an uncertain market demand. The manufacturer bears a unit product cost of $c$ and sells the product to the retailer with a unit wholesale price $w$. For the retailer the unit product's selling price is $r$. At the end of the selling season, there is a salvage market in which any product leftover can be salvaged at anit price $v$. Let the market demand faced by the retailer be $x$ with a probability density function $f(x)$, and a corresponding cumulative distribution function $F(x)$. We assume that there is a one-to-one mapping between $F(\cdot)$ and its argument. We consider the following sequence of action: The manufacturer will first announce the wholesale price and other parameters (with respect to different kinds of contracts) to the retailer, the retailer will react by placing an order with a quantity $q$. We assume that the manufacturer can always fulfil the required order quantity placed by the retailer. For a notational purpose, define:

$$
\xi(q)=2 q \int_{0}^{q} F(x) d x-2 \int_{0}^{q} x F(x) d x-\left(\int_{0}^{q} F(x) d x\right)^{2}
$$

Table 1 below gives the profit, expected profit, standard deviation of profit of the simple supply chain described above. Observe that the manufacturer is risk free and can always make a positive profit when the wholesale price is larger than the production cost under this simple supply chain.

\begin{tabular}{|c|c|c|c|}
\hline & Supply Chain & Retailer & Manufacturer \\
\hline P & $(r-c) q-(r-v)(q-x)^{+}$ & $(r-w) q-(r-v)(q-x)^{+}$ & $(w-c) q$ \\
\hline EP & $(r-c) q-(r-v) \int_{0}^{q} F(x) d x$ & $(r-w) q-(r-v) \int_{0}^{q} F(x) d x$ & $(w-c) q$ \\
\hline SP & $(r-v) \sqrt{\xi(q)}$ & $(r-v) \sqrt{\xi(q)}$ & 0 \\
\hline
\end{tabular}

Table 1. Profit, Expected Profit, and Standard Deviation of Profit of the Simple Supply Chain without Additional Contracts

We now consider two kinds of contracts, the buy-back contract and the wholesale-pricing profit-sharing contract, in the following.

\subsection{Buy-back contract}

Under the buy-back contract, by the end of the selling season, the retailer can return the unsold products to the manufacturer for a partial refund with a unit buy-back price $b$, where $v \leq b<w$. The returned products have a unit value of $v$ to the manufacturer. We can derive the profit, expected profit, and standard deviation of profit under the buy-back contract for 
the supply chain, the retailer, and the manufacturer respectively as shown in Table 2 (see Choi et al. 2008 for the details of derivations).

\begin{tabular}{|c|c|c|c|}
\hline & Supply Chain & Retailer & Manufacturer \\
\hline P & $(r-c) q-(r-v)(q-x)^{+}$ & $(r-w) q-(r-b)(q-x)^{+}$ & $(w-c) q-(b-v)(q-x)^{+}$ \\
\hline EP & $(r-c) q-(r-v) \int_{0}^{q} F(x) d x$ & $(r-w) q-(r-b) \int_{0}^{q} F(x) d x$ & $(w-c) q-(b-v) \int_{0}^{q} F(x) d x$ \\
\hline SP & $(r-v) \sqrt{\xi(q)}$ & $(r-b) \sqrt{\xi(q)}$ & $(b-v) \sqrt{\xi(q)}$ \\
\hline
\end{tabular}

Table 2. Profit, Expected Profit, and Standard Deviation of Profit under the Buy-back Contract

Notice that the supply chain's expected profit and standard deviation of profit are not affected by the presence of the buy-back contract.

\subsection{Wholesale pricing and profit sharing contract}

Under the wholesale pricing and profit sharing contract, the manufacturer controls the wholesale price $w$, where $w$ can be set to be $c$, i.e., the manufacturer is supplying at cost and makes zero profit from the direct supply. On the other hand, the manufacturer will share the retailer's profit with a proportion of $(1-\alpha)$, where $0<\alpha<1$. To be specific, we can derive the following the profit, expected profit and standard deviation of profit under the wholesale pricing and profit sharing contract for the supply chain, the retailer, and the manufacturer, respectively:

\begin{tabular}{|c|c|c|c|}
\hline Supply Chain & Retailer & Manufacturer \\
\hline $\mathrm{P}$ & $(r-c) q-(r-v)(q-x)^{+}$ & $\alpha\left[(r-w) q-(r-v)(q-x)^{+}\right]$ & $\begin{array}{c}(w-c) q+(1-\alpha) \cdot \\
{\left[(r-w) q-(r-v)(q-x)^{+}\right]}\end{array}$ \\
\hline $\mathrm{E}$ & $(r-c) q-(r-v) \int_{0}^{q} F(x) d x$ & $\alpha\left[(r-w) q-(r-v) \int_{0}^{q} F(x) d x\right]$ & $\begin{array}{c}(w-c) q+(1-\alpha) \cdot \\
{\left[(r-w) q-(r-v) \int_{0}^{q} F(x) d x\right]}\end{array}$ \\
\hline $\mathrm{SP}$ & $(r-v) \sqrt{\xi(q)}$ & $\alpha(r-v) \sqrt{\xi(q)}$ & $(1-\alpha)(r-v) \sqrt{\xi(q)}$ \\
\hline
\end{tabular}

Table 3: Profit, Expected Profit, and Standard Deviation of Profit under the Wholesale Pricing and Profit Sharing Contract

\section{Remarks and findings:}

i. Please notice that under both buy-back contract and the wholesale pricing and profit sharing contract, the expected profit functions of both the retailer and supply chain are concave in $q$, and their standard deviation of profit functions are increasing in $q$ (see Choi et al. 2007a for more details).

ii. A direct observation from the expected profit and standard deviation of profit expressions for the manufacturer in Tables 1, 2 and 3 indicates that the manufacturer is basically risk free under the simple supply chain without additional contracts. However, under both the buy-back contract and wholesale pricing and profit sharing 
contract, the manufacturer needs to bear a higher risk. As a result, depending on the degree of risk aversion of the manufacturer, exercising one of these contracts is not always beneficial because the risk level for the manufacturer is higher.

iii. From Tables 1, 2 and 3, we can see that the sum of retailer's SP and manufacturer's SP equals the supply chain's SP. The same applies for the expected profit EP. As a result, a change of the contract parameter, of either the buy-back contract and the wholesale pricing and profit sharing contract, can lead to a reallocation of benefit (expected profit) and risk (standard deviation of profit) between the manufacturer and the retailer. Bargaining power hence plays a crucial role especially for the wholesale pricing and profit sharing contract.

\section{Mean-variance decision models}

We now consider the above proposed supply chain in which the manufacturer acts as a supply chain coordinator. Here, instead of maximizing the supply chain's expected profit, the manufacturer adopts the following MV objective for the supply chain:

$$
\begin{aligned}
& \max _{q} E P_{S C}(q) \\
& \text { s.t. } S P_{S C}(q) \leq k_{S C} .
\end{aligned}
$$

The objective of $(P 1)$ is to maximize the supply chain's expected profit subject to a constraint on the supply chain's standard deviation of profit, where $k_{S C}$ is a positive constant. Represent by $q_{S C, E P^{*}}=F^{-1}[(r-c) /(r-v)]$ the product quantity which maximizes $\operatorname{EP}_{S C}(q)$. The efficient frontier for $(P 1)$ can be constructed with $q \in\left[0, q_{S C, E P^{*}}\right]$, and $\left[0, q_{S C, E P^{*}}\right]$ is the efficient region. In (P1), a smaller $k_{S C}$ implies that the manufacturer (who is the decision maker) is more conservative and risk averse. We thus call $k_{S C}$ the supply chain's risk aversion threshold. Notice that when $k_{S C} \in\left[0, S P_{S C}\left(q_{S C, E P^{*}}\right)\right]$, a smaller value of $k_{S C}$ would lead to a smaller optimal quantity for $(P 1)$ because in this region: $E P_{S C}(q)$ is increasing and concave, $S P_{S C}(q)$ is increasing, and the constraint $S P_{S C}(q) \leq k_{S C}$ is active. When $k_{S C}>S P_{S C}\left(q_{S C, E P^{*}}\right)$, the SP constraint becomes "inactive" as the optimal solution is always $q_{S C, E P^{*}}$. Represent the optimal solution of $(P 1)$ by $q^{*}$. It is easy to show that $q^{*}$ exists and can be uniquely determined (see Choi et al. 2007a for the details). Similar to the model setting in $(P 1)$, the retailer's decision making problem is modelled as follows,

$$
\begin{aligned}
& \max _{q} E P_{R}(q) \\
& \text { s.t. } S P_{R}(q) \leq k_{R} .
\end{aligned}
$$

In $(P 2)$, the retailer tries to maximize his expected profit with the corresponding standard deviation of profit under control, i.e., $S P_{R}(q) \leq k_{R}$, where $k_{R}$ is a positive constant and it is the retailer's risk aversion threshold. When the manufacturer has specified the details on the wholesale price and other contract parameters, the retailer will determine an order quantity $q_{R^{*}}$ which optimizes (P2). Observe that there exists a unique $q_{R, M V^{*}}$ (see Choi et al. 2007a for the details).

In general, $q^{*}$ and $q_{R, M V^{*}}$ are different. In this chapter, we consider the best product quantity for the supply chain in the mean-variance domain as $q^{*}$. As a consequence, the manufacturer 
who acts as the supply chain coordinator can consider using some incentive alignment schemes to try to entice the retailer to order in a quantity which is equal to $q^{*}$. We will now explore how the buy-back contract and the wholesale pricing and profit sharing contract can help to achieve this kind of coordination in a mean-variance domain. We separate the analysis into two parts in the next two sections.

\section{Coordination by the buy-back contract in the mean-variance domain}

Under the presence of the buy-back contract, we rewrite $(P 2)$ into $(P 2(b))$ as follows,

$(P 2(b))$

$$
\begin{aligned}
& \max _{q} E P_{R}[q ; b] \\
& \text { s.t. } S P_{R}[q ; b] \leq k_{R},
\end{aligned}
$$

where $E P_{R}[q ; b]=(r-w) q-(r-b) \int_{0}^{q} F(x) d x, S P_{R}[q ; b]=(r-b) \sqrt{\xi(q)}$ (see Table 2), and $b$ is the buy-back price offered by the manufacturer. Denote the optimal order quantity for $(P 2(b))$ by $q_{R, B B^{*}}(b)$. Following the approach in Choi et al. (2008), for any given $b$, we define the following:

$$
\begin{gathered}
q_{R, 2^{*}}(b)=\underset{q}{\arg }\left\{S P_{R}(q \mid b)-k_{R}=0\right\}, \\
q_{R, 1^{*}}(b)=F^{-1}[(r-w) /(r-b)] .
\end{gathered}
$$

Notice that $q_{R, 1^{*}}(b)$ is the order quantity which maximizes the retailer's expected profit with a given $b$. The following procedure, Procedure 1, provides the steps to identify the buy-back price which can achieve coordination $\left(b_{S C, M V^{*}}\right)$ :

\section{Procedure 1}

Step 1. Compute $q^{*}$ by solving $(P 1)$.

Step 2. Determine a parameter $b_{1^{*}}$ which makes $q_{R, 1^{*}}(b)=q^{*}$ as follows:

$$
\begin{gathered}
q_{R, 1^{*}}(b)=q^{*} \\
\Leftrightarrow F^{-1}[(r-w) /(r-b)]=q^{*} \\
\Leftrightarrow b=r-\left[(r-w) / F\left(q^{*}\right)\right] \\
\therefore b_{1^{*}}=r-\left[(r-w) / F\left(q^{*}\right)\right] .
\end{gathered}
$$

Step 3. Determine a parameter $b_{2^{*}}$ as follows:

$$
\begin{gathered}
q_{R, 2^{*}}(b)=q^{*} \\
\Leftrightarrow S P_{R}\left(q^{*} \mid b\right)-k_{R}=0 \\
\Leftrightarrow(r-b)^{2} \xi\left(q^{*}\right)=k_{R}^{2} \\
\Leftrightarrow b=r-k_{R} / \sqrt{\xi\left(q^{*}\right)} \text { or } b=r+k_{R} / \sqrt{\xi\left(q^{*}\right)} .
\end{gathered}
$$


Since $b<r, b=r+k_{R} / \sqrt{\xi\left(q^{*}\right)}$ is rejected:

$$
\therefore b_{2^{*}}=r-\left(k_{R} / \sqrt{\xi\left(q^{*}\right)}\right) \text {. }
$$

Step 4. Check for the feasibility of $b_{S C, M V^{*}}=b_{1^{*}}$ :

- If $S P_{R}\left(q_{R, 1^{*}} \mid b_{1^{*}}\right) \leq k_{R}$, then $q_{R, B B^{*}}\left(b_{1^{*}}\right)=q_{R, 1^{*}}\left(b_{1^{*}}\right)$. Thus, setting $b=b_{1^{*}}$ would yield $q_{R, B B^{*}}\left(b_{1^{*}}\right)=q_{R, 1^{*}}(b)=q^{*}$. Set $b_{S C, M V^{*}}=b_{1^{*}}$ and stop.

- If $S P_{R}\left(q_{R, 1^{*}} \mid b_{1^{*}}\right)>k_{R}$, then $q_{R, B B^{*}}\left(b_{1^{*}}\right)=q_{R, 2^{*}}\left(b_{1^{*}}\right)$. However, setting $b=b_{1^{*}}$ would not yield $q_{R, B B^{*}}\left(b_{1^{*}}\right)=q^{*}$ since setting $b=b_{1^{*}}$ can only achieve $q_{R, 1^{*}}(b)=q^{*}$, but here $q_{R, B B^{*}}\left(b_{1^{*}}\right)=q_{R, 2^{*}}(b)$. Go to Step 5 .

Step 5. Check for the feasibility of $b_{S C, M V^{*}}=b_{2^{*}}$ (after Step 4):

- If $S P_{R}\left(q_{R, 1^{*}} \mid b_{2^{*}}\right)>k_{R}$, then $q_{R, B B^{*}}\left(b_{2^{*}}\right)=q_{R, 2^{*}}\left(b_{2^{*}}\right)$. Thus, setting $b=b_{2^{*}}$ would yield $q_{R, B B^{*}}(b)=q_{R, 2^{*}}(b)=q_{S C, M V^{*}}$. Set $b_{S C, M V^{*}}=b_{2^{*}}$ and stop.

- If $S P_{R}\left(q_{R, 1^{*}} \mid b_{2^{*}}\right) \leq k_{R}$, then $q_{R, B B^{*}}\left(b_{2^{*}}\right)=q_{R, 1^{*}}\left(b_{2^{*}}\right)$. In this case, setting $b=b_{2^{*}}$ can only achieve $q_{R, 2^{*}}(b)=q^{*}$ (but not $q_{R, 1^{*}}\left(b_{2^{*}}\right)=q^{*}$ which implies $\left.q_{R, B B^{*}}\left(b_{2^{*}}\right)=q^{*}\right)$. Thus, we are not able to achieve $q_{R, B B^{*}}\left(b_{2^{*}}\right)=q^{*}$. In this situation, setting both $b_{S C, M V^{*}}=b_{1^{*}}$ and $b_{S C, M V^{*}}=b_{2^{*}}$ cannot achieve coordination in the MV domain.

Procedure 1 gives us the detailed steps for identifying the buy-back price which can achieve coordination in a mean-variance domain. Since the buy-back price is bounded between $v$ and w, i.e. $v \leq b<w$, a checking on the computed value of $b_{S C, M V^{*}}$ with respect to this bound is a required feasibility test.

\section{Coordination by the wholesale pricing and profit sharing contract in the mean-variance domain}

With the wholesale pricing and profit sharing contract, we rewrite $(P 2)$ into $(P 2(w, \alpha))$ as follows,

$(P 2(w, \alpha))$

$$
\begin{aligned}
& \max _{q} E P_{R}[q ; w, \alpha] \\
& \text { s.t. } S P_{R}[q ; w, \alpha] \leq k_{R},
\end{aligned}
$$

where $E P_{R}[q ; w, \alpha]=\alpha\left[(r-w) q-(r-v) \int_{0}^{q} F(x) d x\right], S P_{R}[q ; w, \alpha]=\alpha(r-v) \sqrt{\xi(q)}$ (see Table 3), $\alpha$ is the proportion of profit that the retailer takes and $w$ is wholesale price offered by the manufacturer to the retailer. Represent the optimal quantity which maximizes $(P 2(w, \alpha))$ by $q_{R, W P^{*}}(w, \alpha)$. Similar to the idea in Section 4 , we define the following:

$$
\begin{gathered}
q_{R, 2^{*}}(w, \alpha)=\underset{q}{\arg \left\{S P_{R}(q \mid w, \alpha)-k_{R}=0\right\},} \\
q_{R, 1^{*}}(w)=F^{-1}[(r-w) /(r-v)] .
\end{gathered}
$$


Notice that $q_{R, 1^{*}}(w)$ is the order quantity which maximizes the retailer's expected profit with a given $w$ and it is independent of $\alpha$. Suppose that $\alpha$ is initially set to be $\alpha_{o}$ (where $\left.0<\alpha_{o}<1\right)$ upon the negotiation between the retailer and the manufacturer. The following procedure gives the steps to identify the wholesale price and/or the necessary adjustment in $\alpha$ in order to achieve coordination in the mean-variance domain:

\section{Procedure 2}

Step 1. Compute $q^{*}$ by solving $(P 1)$.

Step 2. Determine a parameter $w^{*}$ which makes $q_{R, 1^{*}}(w)=q^{*}$ as follows:

$$
\begin{gathered}
q_{R, 1^{*}}(w)=q^{*} \\
\Leftrightarrow F^{-1}[(r-w) /(r-v)]=q^{*} \\
\therefore w^{*}=r-(r-v) F\left(q^{*}\right) .
\end{gathered}
$$

Step 3. Determine a parameter $\alpha^{*}$ which makes $q_{R, 2^{*}}(w, \alpha)=q^{*}$ as follows:

$$
\begin{aligned}
& q_{R, 2^{*}}(w, \alpha)=q^{*} \\
\Leftrightarrow & S P_{R}\left(q^{*} \mid w, \alpha\right)-k_{R}=0 \\
\Leftrightarrow & \alpha(r-v) \sqrt{\xi\left(q^{*}\right)}=k_{R} \\
\therefore & \alpha^{*}=\frac{k_{R}}{(r-v) \sqrt{\xi\left(q^{*}\right)}} .
\end{aligned}
$$

Step 4. Check for the feasibility of setting the wholesale price $w=w^{*}$ with $\alpha=\alpha_{o}$.

- If $S P_{R}\left(q_{R, 1^{*}}\left(w=w^{*}\right) \mid \alpha_{o}\right) \leq k_{R}$, then setting $w=w^{*}$ with $\alpha=\alpha_{o}$ can already make $q_{R, W P^{*}}(w, \alpha)=q^{*}$. Thus, we can set the wholesale price $w=w^{*}$ with $\alpha=\alpha_{o}$, and stop; otherwise, go to Step 5.

Step 5. Check for the feasibility of setting another value of $\alpha$.

- If $S P_{R}\left(q_{R, 1^{*}}\left(w=w^{*}\right) \mid \alpha_{o}\right)>k_{R}$, then:

- Option 1: The manufacturer can try to negotiate with the retailer and set a value of $\alpha=\alpha_{1}$ (where $\left.0<\alpha_{1}<1\right)$ with which $S P_{R}\left(q_{R, 1^{*}}\left(w=w^{*}\right) \mid \alpha_{1}\right) \leq k_{R}$.

- Option 2: The manufacturer can check and see if $\alpha^{*}<1$. If $\alpha^{*}<1$, then the manufacturer can propose to the retailer by setting a value of $\alpha=\alpha^{*}$ (where $\left.0<\alpha^{*}<1\right)$ which can make $q_{R, W P^{*}}(w, \alpha)=q^{*}$.

Procedure 2 provides to us some guidelines for determining the contract parameters of the wholesale pricing and profit sharing contract which can help to achieve coordination in the mean-variance domain. 


\section{Conclusion}

In this chapter, we have conducted a mean-variance analysis for supply chains under a buyback contract and a wholesale pricing and profit sharing contract. We characterize in the supply chain the return and the risk by the expected profit and the standard deviation of profit, respectively. We focus our discussions on the centralized supply chains. From the structural properties of the supply chain, we find that the buy-back price and the wholesale price are simply internal money transfers between the retailer and the manufacturer. A change of these prices will lead to a change of the profit and risk sharing between the retailer and the manufacturer. We illustrate how a buy-back contract and a wholesale pricing and profit sharing contract can coordinate a supply chain in a mean-variance domain. Efficient procedures are proposed. The necessary and sufficient conditions for the optimal contract parameters to be found in its feasible region can then be determined. Observe that channel coordination in the mean-variance domain is not always achievable. This finding is important because when we ignore the risk aversions of the individual supply chain members (as what most papers in the literature assume), channel coordination can always be achieved by setting a buy-back contract and a wholesale pricing and profit sharing contract. However, in the real-world, different supply chain members have different degrees of risk aversion, and hence a realistic contract should be set with respect to the risk aversions of these individual decision makers. Moreover, intuitively, when the risk aversions between the supply chain coordinator and the retailer are too far away, channel coordination may not be achievable and this point can be revealed by using our analytical models. From the studies in this chapter, we can see that the mean-variance model can provide a systematic framework for studying channel coordination issues in stochastic supply chain models with risk and profit considerations. This framework can be further extended and used to study a large variety of supply chain contracts.

\section{References}

Choi, T.M., Li, D. \& Yan, H. (2007a). Mean-Variance Analysis of Newsvendor Problem. To appear in IEEE Transactions on Systems, Man, and Cybernetics: Part A.

Choi, T.M., Li, D. \& Yan, H. (2008). Mean-variance analysis of a single supplier and retailer supply chain under a returns policy. European Journal of Operational Research, 184, 356-376.

Choi, T.M., Li, D., Yan, H. \& Chiu, C.H. (2007b). Channel coordination in supply chains with agents having mean-variance objectives. Forthcoming in Omega, available online in ScienceDirect.com, doi : 10.1016/j.omega.2006.12.003.

Agrawal, V. \& Seshadri, S. (2000). Risk intermediation in supply chains. IIE Transactions, 32, 819-831.

Bassok, Y. \& Nagarajan, M. (2004). Contracting under risk preferences. Working paper, University of Southern California.

Buzacott, J., Yan, H. \& Zhang, H. (2003). Risk analysis of commitment-option contracts with forecast updates. Working paper, York University.

Cachon, GP. (2003). Supply chain coordination with contracts. Working paper, University of Pennsylvania,

Chen, F. \& Federgruen, A. (2000). Mean-variance analysis of basic inventory models. Working paper, Columbia University. 
Eeckhoudt, L., Gollier, C. \& Schlesinger, H. (1995). The risk averse (prudent) newsboy. Management Science, 41, 786-794.

Kroll, Y., Levy, H. \& Markowitz, H.M. (1984). Mean-variance versus direct utility maximization," Journal of Finance, 39, 47-61.

Lau, H.S. (1980). The newsboy problem under alternative optimization objectives. Journal of the Operational Research Society, 31, 525-535.

Lau, H.S. \& Lau, A.H.L. (1999). Manufacturer's pricing strategy and returns policy for a single-period commodity. European Journal of Operational Research, 116, 291-304.

Levy, H. \& Markowitz, H.M. (1979). Approximated expected utility by a function of mean and variance. American Economics Review, 69, 308-317.

Luenberger, DG. (1998). Investment Science. Oxford University Press.

Markowitz, H.M. (1959) Portfolio Selection: Efficient Diversification of Investment. New York: John Wiley \& Sons.

Pasternack, B.A. (1985). Optimal pricing and returns policies for perishable commodities. Marketing Science, 4, 166-176.

Roy, A.D. (1952). Safety first and the holding of assets. Econometrica, 20, 431-449.

Smeltzer, L.R. \& Siferd, S.P. (1998). Proactive supply management: The management of risk. International Journal of Purchasing \& Materials Management, Winter, 38-45.

Tan, B. (2002). Managing manufacturing risks by using capacity options. Journal of the Operational Research Society, 53, 232-242.

Tsay, A.A., Nahmias, S. \& Agrawal, N. (1999). Modelling supply chain contracts: a review. In: Quantitative Models for Supply Chain Management, Tayur S et al. (Eds), Kluwer Academic Publishers, 299-336.

Van Mieghem, J.A. (2003). Capacity management, investment, and hedging: Review and recent developments. Manufacturing and Service Operations Management, 5, 269-301.

Webster, S. \& Weng, Z.K. (2000). A risk-free perishable item returns policy. Manufacturing and Service Operations Management, 2, 100-106.

\section{Acknowledgements}

This work is partially supported by the RGC Competitive Earmarked Research Grant PolyU5146/05E, and the internal fundings provided by the Hong Kong Polytechnic University. The author would like to dedicate this piece of work to Bryan Choi. 


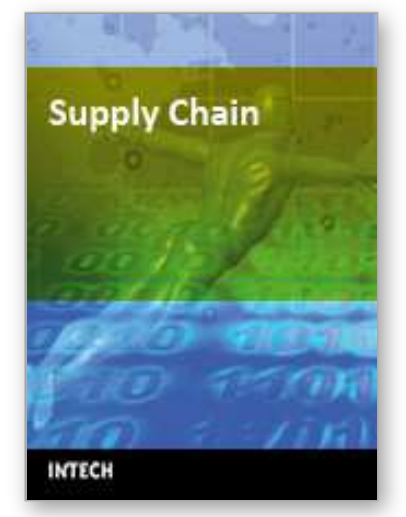

\author{
Supply Chain \\ Edited by Vedran Kordic
}

ISBN 978-3-902613-22-6

Hard cover, 568 pages

Publisher I-Tech Education and Publishing

Published online 01, February, 2008

Published in print edition February, 2008

Traditionally supply chain management has meant factories, assembly lines, warehouses, transportation vehicles, and time sheets. Modern supply chain management is a highly complex, multidimensional problem set with virtually endless number of variables for optimization. An Internet enabled supply chain may have justin-time delivery, precise inventory visibility, and up-to-the-minute distribution-tracking capabilities. Technology advances have enabled supply chains to become strategic weapons that can help avoid disasters, lower costs, and make money. From internal enterprise processes to external business transactions with suppliers, transporters, channels and end-users marks the wide range of challenges researchers have to handle. The aim of this book is at revealing and illustrating this diversity in terms of scientific and theoretical fundamentals, prevailing concepts as well as current practical applications.

\title{
How to reference
}

In order to correctly reference this scholarly work, feel free to copy and paste the following:

Tsan-Ming Choi (2008). Mean-Variance Analysis of Supply Chain Contracts, Supply Chain, Vedran Kordic (Ed.), ISBN: 978-3-902613-22-6, InTech, Available from:

http://www.intechopen.com/books/supply_chain/mean-variance_analysis_of_supply_chain_contracts

\section{INTECH}

open science | open minds

\section{InTech Europe}

University Campus STeP Ri

Slavka Krautzeka 83/A

51000 Rijeka, Croatia

Phone: +385 (51) 770447

Fax: +385 (51) 686166

www.intechopen.com

\section{InTech China}

Unit 405, Office Block, Hotel Equatorial Shanghai

No.65, Yan An Road (West), Shanghai, 200040, China 中国上海市延安西路65号上海国际贵都大饭店办公楼 405 单元

Phone: +86-21-62489820

Fax: +86-21-62489821 
(C) 2008 The Author(s). Licensee IntechOpen. This chapter is distributed under the terms of the Creative Commons Attribution-NonCommercialShareAlike-3.0 License, which permits use, distribution and reproduction for non-commercial purposes, provided the original is properly cited and derivative works building on this content are distributed under the same license. 